Research Paper

\title{
Antioxidant Activity Analysis and Standardization of Parkia speciosa (Petai) Pods Ethanol Extract
}

\author{
Najma Annuria Fithri ${ }^{1}$, Fitrya ${ }^{1}$, Tia Shabrina ${ }^{2}$, Atika Akbari $^{2}$, Diva Yulanri ${ }^{1}$ \\ ${ }^{1}$ Department of Pharmacy, Sriwijaya University, Inderalaya, Ogan Ilir, Sumatera Selatan, Indonesia \\ ${ }^{2}$ Department of General Medicine, Sriwijaya University, Inderalaya, Ogan Ilir, Sumatera Selatan, Indonesia \\ *Corresponding author: empith@gmail.com
}

\begin{abstract}
Parkia speciosa (petai) pods are rarely used and considered as waste despite their phenolic and flavonoid content. Phenolic and flavonoid content in plants are known to exhibit antioxidant activity. Antioxidants are known to potentially act against radical and mediate the damage by structural stabilization. This research was conducted to analyze the antioxidant potential of petai pods using DPPH method. Analysis showed the $\mathrm{IC}_{50}$ of petai pods ethanolic extract was 75.72 ppm, which indicate strong acting antioxidant. Standardization of extracts was determined to manage the quality of extract, including the analysis of density, water content, ash values, and quantification of total phenolic and flavonoid content. Research outcome indicates the extract retain its quality during storage and use which confirmed to the standardization requirements of water content and ash values. Total phenolics and flavonoid obtained were $272.45 \mathrm{mg} / \mathrm{gGAE}$ and $243.2029 \mathrm{mg} / \mathrm{gQE}$ respectively. Based on this research, petai pods ethanolic extract present strong antioxidant activity which was contributed by the high existing content of flavonoid and phenolic compounds.
\end{abstract}

\section{Keywords}

antioxidant, Parkia speciosa, petai pod, standardization, total flavonoid, total phenolic

Received: 5 September 2018, Accepted: 30 September 2018

https://doi.org/10.26554/sti.2019.4.1.5-10

\section{INTRODUCTION}

Parkia speciosa or indigenously known as petai Indonesia has been empirically consumed and used for everyday diet or medicinal purpose. However, the utilization of the pod has been limited despite previous research showing positive screening result of the phytochemical compound such as phenolics and flavonoids. Earlier research by Vimala and Adenan (1999) of petai seeds and leaves indicate strong antioxidant activity against the radical effect of superoxide with an inhibition rate around $70 \%$. However, research towards petai pods have not been conducted, thus utilization of the petai pods as a source of natural antioxidants is very promising and needs to be investigated further. Antioxidants are useful in many therapeutic uses such as cancer, infection as well as degenerative diseases such as dementia or Alzheimer. Therefore, continuous research towards findings and screening of antioxidant materials are crucial.

In order to maintain and replicate the process of extraction to obtain a good quality extract, standardization is one of the methods to quantify and determine the result. Density, water content, ash values, and thin layer chromatography (TLC) analysis were performed. Tests conducted in the form of total phenolic, total flavonoid, and antioxidant activity test. The total phenolic test was conducted using Folin-Ciocalteu method, total flavonoid test using $\mathrm{AlCl}_{3}$ staining method, and antioxidant activity test using DPPH method.

\section{EXPERIMENTAL SEGTION}

\subsection{Materials}

Materials used includes petai pod (Parkia speciosa Hassk.) obtained from Perlang Village, Koba Sub-District, Bangka Belitung in August 2017, pro analysis grade solvents, and pro analysis grade reagents which include Folin-Ciocalteu for phenolic content analysis and 1,1-diphenyl-2-picrylhydrazyl (DPPH) for antioxidant activity analysis. Comparative standards quercetin, gallic acid, and ascorbic acid used in this research are all analytical grade. Instruments used in this research are stapled laboratory instruments, rotary evaporator, and UVVis spectrophotometer.

\subsection{Sampling and Extraction}

Samples of petai pod's peel were wet sorted and dried under the sun. Dried samples were then pollinated and weighed as much as $1 \mathrm{~kg}$. Dry pod skin peel was extracted with maceration method for $2 \times 24$ hours using $70 \%$ ethanol solvent with a 
ratio of 1: 7.5 and repeated until the solvent turns clear. The obtained yield was concentrated by evaporating the solvent using a rotary evaporator at $70{ }^{\circ} \mathrm{C}$ to avoid degradation of phytochemicals.

$$
\text { PercentYield }=\frac{\text { extractweight }}{\text { simpliciaweight }} x 100 \%
$$

\subsection{Standardization of Extract}

2.3.1 Determination of Water-Soluble and Ethanol-Soluble Content

To analyze the water-soluble content, extract as much as 1 g macerated pod skin peel with a solvent which contains 25 $\mathrm{mL}$ of chloroform in $1 \mathrm{~L}$ of water for 24 hours by using a measuring flask while repeatedly shaken for the first 6 hours. Leave the extract in room temperature for 18 hours before being filtered. The filtrate of $5 \mathrm{~mL}$ was evaporated in a tarred vapor bowl until the solvent evaporated. Heat the residue at $105^{\circ} \mathrm{C}$ until the weight stays constant. A similar process was applied for the determination of ethanol-soluble content, but the solvent used in maceration was $25 \mathrm{~mL}$ of $96 \%$ ethanol.

\subsubsection{Total Ash Content}

A total of $1 \mathrm{~g}$ of extract was placed on the furnace. Gradually increase the temperature up to $600 \pm 25^{\circ} \mathrm{C}$ until the charcoal runs out and then weigh until constant weight.

\subsubsection{Acid Insoluble Ash Content}

The ash sample from total ash content analysis was boiled in $25 \mathrm{~mL}$ diluted hydrochloric acid for 5 minutes. Insoluble residue was collected with ash-free filter paper and rinsed with hot water. Cool down the temperature until the weight stays constant.

\subsubsection{Density}

Clean and dry pycnometer was calibrated by determining pycnometer weight and freshly boiled water at room temperature. The diluted extract was set to $20^{\circ} \mathrm{C}$ and placed into the empty pycnometer. Then remove the excess extract, set the temperature of the pycnometer that has been filled to $25^{\circ} \mathrm{C}$ and weigh it.

\subsubsection{Water Content}

Extract $1 \mathrm{~g}$ of sample in a closed porcelain crucible which have been preheated at $105^{\circ} \mathrm{C}$ for 30 minutes, trimmed, and flattened to a layer of $10-15 \mathrm{~mm}$. Dry the sample at a fixed temperature until reaching the constant weight. The cruses are left closed and cooled in the desiccator at room temperature. Record the weights to calculate the percentage of shrinkage.

\subsubsection{Determination of Total Phenolic Content}

The primary solution of gallic acid was made with a concentration of $1000 \mathrm{ppm}$. Then, main liquor was diluted with methanol:water $(1: 1)$ resulting in concentration levs of 50, 100, 150,200 , and $250 \mathrm{ppm}$ of gallic acid. Take $100 \mu \mathrm{L}$ from each concentration level sample and add $3.95 \mathrm{~mL}$ of distilled water,
$0.25 \mathrm{~mL}$ of Folin-Ciocalteu reagent, and leave for 8 minutes. Mix the samples with $0.75 \mathrm{~mL}$ of $20 \% \mathrm{Na}_{2} \mathrm{CO}_{3}$ solution, shake homogeneously, and incubate for 30 minutes at $37^{\circ} \mathrm{C}$. The maximum wavelength of the error acid was determined by observing the wavelength of each concentration samples at 400 - $800 \mathrm{~nm}$ (Waterhouse, 1999).

2.3.7 Determination of Phenolic Content of Total Sample Ethanol extract of $250 \mathrm{ppm}$ petai pod was dissolved with methanol:water (1:1). Take $100 \mu \mathrm{L}$ of solution, add $3.95 \mathrm{~mL}$ of distilled water and $0.25 \mathrm{~mL}$ of Folin-Ciocalteu reagent, then leave it for 8 minutes. Add $0.75 \mathrm{~mL}$ of $20 \% \mathrm{Na}_{2} \mathrm{CO}_{3}$ solution, shake homogeneously, incubate for 30 minutes at $37^{\circ} \mathrm{C}$. The absorption was measured with $\mathrm{UV}-\mathrm{V}$ is spectrophotometer at a wavelength of $766 \mathrm{~nm}$ and was characterized by the formation of blue complex.

\subsection{Determination of Total Flavonoid}

\subsubsection{Maximum Wavelength Determination}

Select one of the solutions at a certain concentration level and measure it between the 400 - $800 \mathrm{~nm}$ wavelength range. Maximum wavelength indicates high absorption value.

\subsubsection{Determination of the Quercetin Standard Curve}

Standard solution of quercetin was prepared from a standard solution of $100 \mathrm{ppm}$ with concentration levels: 1, 5, 10, 20, and $40 \mathrm{ppm}$. A total of $0.10 \mathrm{ml}$ of $10 \%$ aluminum chloride, $0.10 \mathrm{ml}$ of $1 \mathrm{M}$ sodium acetate, and $2.80 \mathrm{ml}$ of distilled water was added. The mixture was left for 30 minutes, while the absorption was processed with UV-Vis spectrophotometer at $441 \mathrm{~nm}$. Linear regression method was used to obtain the equation $\mathrm{Y}=\mathrm{a}+\mathrm{bX}$, with the concentration of extract (ppm) as axis (X-axis) and the absorbance of the test solution as ordinate (Y-axis).

\subsubsection{Determination of Total Flavonoid Content}

Petai pod ethanol extract $(5 \mathrm{mg}$ ) was dissolved in methanol p.a. up to $5 \mathrm{~mL}$ (concentration $1000 \mathrm{ppm}$ ) and diluted to a concentration of $100 \mu \mathrm{g} / \mathrm{mL}$. The sample of ethanol extract of petai skin was dissolved with methanol p.a $(2-5 \%)$, mixed with $0.10 \mathrm{ml} 10 \%$ aluminum chloride, $0.10 \mathrm{ml}$ of $1 \mathrm{M}$ sodium acetate, and $2.80 \mathrm{ml}$ of distilled water. The mixture was left for 30 minutes and then measured its absorption using $\mathrm{UV}-\mathrm{V}$ is spectrophotometer at $441 \mathrm{~nm}$.

\subsection{Antioxidant Activity Test}

\subsubsection{Scanning Wavelength of DPPH}

A total of $1 \mathrm{~mL}$ DPPH $0.3 \mathrm{mM}$ solution was added with 2.5 $\mathrm{ml}$ of methanol p.a, shaken homogeneously in a test tube, and left for 30 minutes in a dark room. The maximum wavelength was measured between 400 - $700 \mathrm{~nm}$ range.

\subsubsection{Determination of Comparative Sample Antioxidant Activities}

A total of $100 \mu \mathrm{g} / \mathrm{mL}$ of each quercetin and vitamin $\mathrm{C}$ were used as the samples. The antioxidant activity test of these 
samples was prepared in various concentration levels: $2,4,6,8$, and $10 \mu \mathrm{g} / \mathrm{mL}$ solutions from the main liquor. One $\mathrm{mL}$ of 0.3 $\mathrm{mM}$ DPPH solution was added with $2.5 \mathrm{~mL}$ of samples from each concentration and stored for $30 \mathrm{~min}$ in a dark room. The absorption was measured using UV-Vis spectrophotometer with $\lambda$ maximum of DPPH $517 \mathrm{~nm}$. Antioxidant activity of the sample is determined by the amount of DPPH radical uptake resistance by calculating the percentage of DPPH uptake inhibition.

$$
\% \text { inhibition }=\frac{\text { abscontrol }- \text { abssample }}{\text { abscontrol }} \times 100 \%
$$

$\mathrm{IC}_{50}$ value is determined using the regression method. Regarding the data of percentage of inhibition obtained, linear regression method was applied to get the equation $\mathrm{Y}=\mathrm{aX}+\mathrm{b}$, with extract concentration (ppm) as axis (X-axis) and value of $\%$ inhibition (antioxidant) as ordinate (Y-axis).

\section{6 $\mathrm{IC}_{50}$ Antioxidant Petai Pods}

Samples were prepared in various concentration levels: 20, 40, 60,80 , and $100 \mu \mathrm{g} / \mathrm{mL}$ from the main liquor. One $\mathrm{mL}$ of 0,3 $\mathrm{mM}$ DPPH solution was added with $2.5 \mathrm{~mL}$ of sample from each concentration and stored in a dark room for 30 minutes. The absorption was measured using $\mathrm{UV}-\mathrm{V}$ is with $\lambda$ maximum at $517 \mathrm{~nm}$. Calculation of \% inhibition and $\mathrm{IC}_{50}$ samples were the same as the comparison samples.

\section{RESULTS AND DISCUSSION}

\subsection{Extraction}

Firstly, the dried petai pod sample was flattened thus the surface area is larger, resulting in the maximum extraction process. The extraction used maceration method with ethanol forming $70 \%$ of the solvent, so the polar flavonoid compounds up to the desired semi-polar of the plant may be perfectly attracted.

The solvent can penetrate the cell wall way through the cell cavity containing the active substance. Compound will dissolve because of the concentration difference between active substance solution inside and outside the cell, causing the concentrated solution to pushed out. This process was performed repeatedly until reaching the concentration balance between the solution outside and inside the cell. Maceration process is carried out for $2 \times 24$ hours with the remaceration done until the clear sample solution indicates that the active substance in the sample has been extracted optimally (Kamisah et al., 2013).

The extract yield resulted 19,66\% with the thickness of thick skin extract of petai fruit equal to $0,1966 \mathrm{~kg}$. Determination of this rendement aims to predict the amount (weight) of simplicial needs for the manufacture of herbal medicine ingredients in a drug preparation. The yield of rendement can also indicate the possible amount of chemical compounds contained in the extract.

\subsection{Standardization of Petai Pods Ethanol Extract}

Standardization is a set of parameters and measurement of elements related to quality paradigms that meet the standard

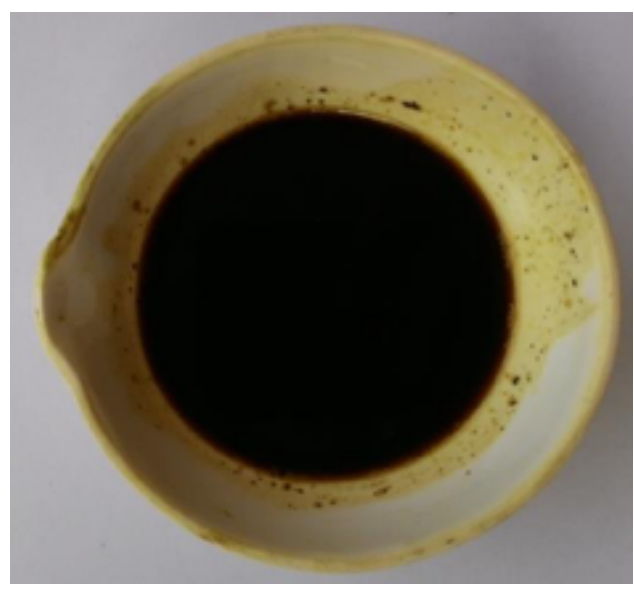

Figure 1. Petai pods ethanolic extract

requirements. Standardization is important to ensure the uniformity of efficacy through the assurance of the levels of active compounds through quantitative analysis of secondary metabolites, ensuring safety aspects, extract stability, and increase the economic value of extracts. The result of the standardization of extract can be seen in Table 1 .

Table 1. Result of standardization of petal skin ethanol extract

\begin{tabular}{ll}
\hline Parameter & Result \\
\hline Water content & $7,97 \%$ \\
Water soluble content & $25,0 \%$ \\
Ethanol soluble con- & $33,3 \%$ \\
tent & \\
Total ash content & $6,29 \%$. \\
Ash content not soluble & $1,98 \%$ \\
acid & \\
\hline
\end{tabular}

Organoleptic parameters are determined to give the initial introduction of the extract objectively. According to the test, it is known that the extract of ethanol skin of petai fruit obtained in the form of thick extract such as jam, greenish-brown color, does not sting bad but does have a bitter taste. The blackishgreen brown color obtained is due to the color change of the plant when it is dried and soaked with the liquid of the dancer. Typical smell is weak and not stinging and bitter taste can be caused by ethanol extract of petai petai skin contains alkaloid compound.

Determination of water-soluble and ethanol content aims to provide an initial description of the number of compounds that can be sought with water solvents and ethanol from a simplicia or an extract. Water-soluble extract content of $25 \pm 0.707 \%$, while the ethanol soluble content of $33.3 \pm 0.235 \%$. This shows that the amount of polar (water-soluble) compounds such as saponins in the extract is less than the ethanol-soluble and semipolar compounds such as alkaloids, non-polar flavonoids such as steroids. 
Measurement of moisture content is carried out to determine the residual water after the thickening or drying process. High levels of water contained in the extract can lead to the growth of fungi, bacteria, or other microorganisms that can affect the quality of the extract. The result of moisture content determination of banana fruit ethanol extract was $7.973 \pm$ $0.037 \%$. The water content of ethanol extract of petai skin is considered eligible since it is good for long period storage until maximum $10 \%$.

The weight of the extract type is calculated using a pycnometer. In order not to affect the results of research, pycnometer usage must be completely clean and dry. The weight of the type is defined as the ratio of the density of a substance to the water density by the value of time per unit volume. Determination of this type of weight aims to provide a description of the dissolved chemical content in from the extraction process. Based on the research, we get the weight of the extract type of $1.019 \pm 0.0048 \mathrm{~kg} / \mathrm{cm}^{3}$ which indicates that the weight of extract type is higher than water.

Determination of total ash content aims to provide an overview of internal and external mineral content derived from the initial process until the formation of the extract. The extract is heated to an organic compound and its derivatives are destructible and evaporate until only inorganic and mineral elements remain. The result of standardization of total ash content of extract was obtained at $6.29 \pm 0.453 \%$. It is stated that the ash content of ethanol extract of petai peel skin fulfills a predetermined condition.

Acid-insoluble ash test is intended to dissolve calcium carbonate and alkali chloride, whereas the total insoluble substance in acid usually contains silicate derived from soil or sand. The amount of dirt, soil, clay, and others contained in the test sample referred as a foreign inorganic substance that is formed or attached to the extract when the extraction process is carried out. The result of acid soluble ash content obtained is 1,9867 $\pm 0,0094 \%$.

\subsection{Identification of Flavonoids using TLC}

Identification of flavonoids in ethanol extract of petai petai skin using thin layer chromatography (TLC). The stationary phase used in the experiments was silica, while the mobile phase used was toluene: ethyl acetate (3:7). Flavonoid compound group examinations were detected under $366 \mathrm{~nm}$ and $254 \mathrm{~nm} \mathrm{UV}$ light.

Spray reagents used to identify flavonoid compounds include cerium sulfate and $\mathrm{AlCl}_{3}$. According to Harborne (1998), the presence of flavonoid compounds is characterized by spots that are yellow to brown in visible light and blue fluorescence on $366 \mathrm{~nm}$ UV rays. Based on the results of extract chromatogram with spray, cerium sulfate reagent showed a brownish yellow color. This indicates that there is a flavonoid compound in a petal leaf ethanol extract. The color that occurs is due to the presence of bonds or substituted hydroxyl groups on $\mathrm{C} 6-\mathrm{C}$ 3-C 6 rings with positively charged Ce (cerium) (Harborne, 1998).

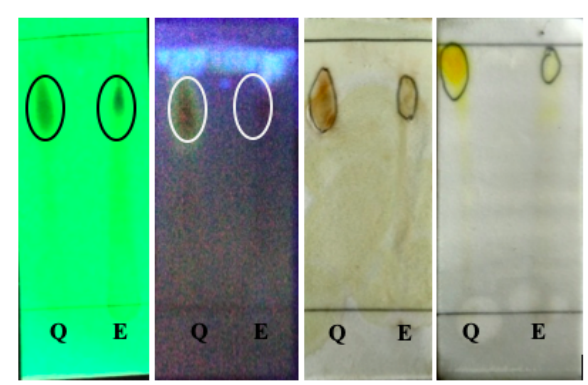

Figure 2. TLC results of ethanol extract of petai pod (a) UV 254 (b) UV 366 (c) seal of cerium sulfate stain (d) $\mathrm{AlCl}_{3}$ stain appearance. $Q=$ quercetin; $E=$ extract

In addition to cerium sulfate, another stain was used in the form of aluminum chloride. One characteristic of flavonoid compounds is its ability to form a chelate. The flavonoid compound in the ethanol extract of the petai skin will bind to aluminum (Al) to form a yellow stable complex (Harborne, 1998). Based on the test, it is known that the extract of ethanol skin of positive petai fruit contains flavonoid compound.

\subsection{Determination of Total Phenolic Content of Ethanol Extracts of Petai Pods}

Determination of total phenolic content of petai pod ethanol extract was done using Folin-Ciocalteu method following Sun et al. (2015) and Mahmoudi et al. (2016) procedure. The principle of this method is based on the reduction of the phosphotungstate mix reagent $\left(\mathrm{WO}_{4}^{2-}\right)$ and phosphomolybdate $\left(\mathrm{MoO}_{4}^{2-}\right)$ with the phenolic hydroxyl group producing the blue product. The intensity of the color is then quantified based on the absorbance with the spectrophotometer (Viranda, 2009).

Total phenol test aims to determine the total phenolic compounds contained in the extract. A sodium bicarbonate solution used to make the atmosphere alkaline. Samples that have been added reagents and sodium bicarbonate will change color to blue. This is caused by the reaction involving the oxidation of the phenolic group ( $\mathrm{ROH}$ ) with a mixture of phosphotungstic acid and molybdic acid in the reagent, into a quinoid $(\mathrm{R}=\mathrm{O})$ form of blue.

Petai pod total phenolic content was obtained from the linear regression equation on absorbance of gallic acid concentration. Gallic acid used as a standard of measurement due to its state as a derivative of hydroxybenzoic acid belonging to simple phenolic acids, thus it is effective to form complex compounds with Folin-Ciocalteu reagents. In addition, the gallic acid has a more stable and pure form.

This research obtained a linear regression equation $\mathrm{y}=$ $0.0003 x+0.1675$ with correlation coefficient of 0.992 . The linear regression equation is derived from making a standard steam curve. Phenolic content of banana peel extract based on the equation was $272.45 \mathrm{mg} \mathrm{GAE} / \mathrm{g}$. It is stated that, in each gram of extract equivalent to $272.45 \mathrm{mg}$ of gallic acid. The content of phenolic compounds in the petroleum ethanol 
extract of petai fruit is quite high because it is greater than 200 $\mathrm{mg}$ GAE/g. This states that the higher the content of phenolic compounds in the extract, the higher the antioxidant power.

\subsection{Determination of Total Flavonoids of Ethanol Extracts of Petai Pods}

Measurement of total flavonoid content of petai petai fruit extract was done by $\mathrm{AlCl}_{3}$ staining method. The principle of this staining method is that $\mathrm{AlCl}_{3}$ forms a stable acid complex with a keto group on $\mathrm{C}-4$, then with a $\mathrm{C}-3$ or $\mathrm{C}-5$ hydroxyl group of flavones and flavonols. In addition, $\mathrm{AlCl} 3$ also forms a labile acid complex with ortho dihydroxyl groups in A or B rings of flavonoids (Fessenden and Fessenden, 1998)

The manufacture of calibration curves using the $\mathrm{AlCl}_{3}$ method using quercetin as a comparator because quercetin is a flavonoid group having keto groups in C-4 and has a hydroxy group on $\mathrm{C}-3$ or $\mathrm{C}-5$ neighboring from flavones and flavonols. Based on the maximum wavelength scanning, we get $441 \mathrm{~nm}$ quercetin wavelength.

This research resulted a linear regression value with equation $y=0,023 x-0,011$. Based on the linear regression equation, obtained total flavonoid extract ethanol skin of petai fruit equal to $243,2029 \mathrm{mg} / \mathrm{g}$. It is stated that the extract of ethanol skin of petai fruit has high flavonoid levels. High levels of flavonoids in the extract potentially have high antioxidant power, concurrently shows free radicals.

\subsection{Antioxidant Activity Test of Ethanol Extract of Petai Pods}

DPPH method was used to test the antioxidant activity of petai pod ethanol extract. The purpose of this method is to know the equivalent concentration parameters to give a $50 \%$ effect of antioxidant activity $\left(\mathrm{IC}_{50}\right)$. DPPH is a free radical that can react with a compound that can donate a hydrogen atom and can be useful for testing the antioxidant activity of specific components in an extract.

Antioxidant compounds can change the color of DPPH solution from purple to yellow (Dehpour et al., 2009). The DPPH method is an easy, fast, and sensitive method for testing the antioxidant activity of certain compounds or plant extracts (Koleva et al., 2010). Extracts containing antioxidants will bind DPPH which is as free radical.

Antioxidant testing is conditioned on dark space to maintain stability and minimize DPPH damage due to light. The measurement of DPPH wavelength was performed using a concentration of $0.3 \mathrm{mM}$ DPPH solution. Scanning the maximum absorption wavelength of DPPH is measured at 400 $800 \mathrm{~nm}$ visible wavelength. The wavelength scanning results obtained for $517 \mathrm{~nm}$, this is in accordance with the research Blois (1958).

Based on the research, $\mathrm{IC}_{50}$ antioxidant value obtained from the ethanol extract of petai skin is relatively stable at $75.72 \mu \mathrm{g} / \mathrm{mL}$. While quercetin as a comparison of 2.2406 $\mu \mathrm{g} / \mathrm{mL}$, donepezil of $4.5159 \mu \mathrm{g} / \mathrm{mL}$, and vitamin $\mathrm{C}$ of 1.3439 $\mu \mathrm{g} / \mathrm{mL}$. Fruit antioxidant content of petai fruit has a relatively strong activity with a range of 50 to $100 \mu \mathrm{g} / \mathrm{mL}$.

Table 2. $\mathrm{IC}_{50}$ antioxidant ethanol extract of petai pod and comparison

\begin{tabular}{lll}
\hline Sample & Equation & $\begin{array}{l}\mathrm{IC}_{50} \\
(\mu \mathrm{g} / \mathrm{mL})\end{array}$ \\
\hline $\begin{array}{l}\text { Ethanol extract of petai } \\
\text { pods }\end{array}$ & $\mathrm{Y}=0.657 \mathrm{x}+75.72$ \\
Quersetin & 0.250 \\
& $\mathrm{Y}=6.173 \mathrm{x}+2.2406$ \\
Vitamin C & 36.16 \\
& $\mathrm{Y}=4.323 \mathrm{x}+1.3439$ \\
Donepezil & 44.19 \\
& $\mathrm{Y}=9.647 \mathrm{x}+4.5159$ \\
& 6.433 \\
\hline
\end{tabular}

$\mathrm{IC}_{50}$ value of an antioxidant compound is inversely proportional to its antioxidant activity. The smaller antioxidant activity indicates an even greater $\mathrm{IC}_{50}$ value. The amount of IIC $_{50}$ quercetin, vitamin $\mathrm{C}$, and donepezil is lower than the ethanol extract of petai pod because it is a pure compound, while the extract is still in the form of a mixture of several compounds. The antioxidant activity of the natural material compound is influenced by the hydroxyl group contained in the compound. The more free hydroxyl groups that can donate hydrogen, the more reduction a compound can do to DPPH (Molyneux, 2003).

\section{CONGLUSIONS}

The ethanol extract of the pod of the petai pods prescribed terms and standards. Water-soluble content obtained $25 \pm$ $1.414 \%$ while soluble ethanol extract of $33.35 \pm 0.47 \%$. Total ash content $6.29 \pm 0.453 \%$, acid unsaturated degree $1.98 \pm$ $0.0094 \%$, weight type $1.019 \pm 0.0041 \%$, and water content of $7.97 \pm 0.037 \%$. The total phenolic compound content of ethanol extract of petai pods is $272,45 \mathrm{mg} / \mathrm{g}$ and total flavonoid obtained was $243,2029 \mathrm{mg} / \mathrm{g}$. IC50 antioxidant ethanol extract of petai pod belongs to high activity that is $75,72 \mu \mathrm{g} / \mathrm{mL}$. This result indicates the potential of petai pods as a strong antioxidant with favorable characteristics to be developed further.

\section{ACKNOWLEDGEMENT}

Authors would like to express their gratitude toward Sriwijaya University PNPB Sains Teknologi dan Seni (SATEKS) Research Grant that made this research possible.

\section{REFERENCES}

Blois, M. (1958). Antioxidant determinations by the use of a stable free radical. Nature, 181; 1199-1200

Dehpour, A., M. Ebrahimzadeh, N. Fazel, and N. Mohammad (2009). Antioxidant activity of methanol extract of ferula assafoetida and its essential oil composition. Grasas y Aceites, 60(4); 405-412 
Fessenden, R. and J. Fessenden (1998). Organic Chemistry. Brooks/Cole Publishing Company, Wisconsin, US.

Harborne, A. (1998). Phytochemical Methods: A Guide to Modern Techniques of Plant Analysis. Springer Science \& Business Media, Berlin, Germany

Kamisah, Y., F. Othman, H. M. S. Qodriyah, and K. Jaarin (2013). Parkia speciosaHassk.: A Potential Phytomedicine. Evidence-Based Complementary and Alternative Medicine, 2013; 1-9

Koleva, I. I., T. A. van Beek, J. P. H. Linssen, A. de Groot, and L. N. Evstatieva (2010). Screening of plant extract for antioxidant activity: A comparative study on tree testing methods. Phytochemical Analysis, 13(1); 8-17

Mahmoudi, S., M. Khali, A. Benkhaled, K. Benamirouche, and I. Baiti (2016). Phenolic and flavonoid contents, antioxidant and antimicrobial activities of leaf extracts from ten Algerian Ficus carica L. varieties. Asian Pacific Journal of Tropical Biomedicine, 6(3); 239-245

Molyneux, P. (2003). The use of the stable free radical diphenylpicrylhydrazyl (DPPH) for estimating antioxdant activity. Journal of Science and Technology, 26(2); $211-219$

Sun, C., Z. Wu, Z. Wang, and H. Zhang (2015). Effect of Ethanol/Water Solvents on Phenolic Profiles and Antioxidant Properties of Beijing Propolis Extracts. Evidence-Based Complementary and Alternative Medicine, 2015; 1-9

Vimala, S. and M. Adenan (1999). Malaysian tropical forest medicinal plants: a source of natural antioxidants. Journal of Tropical Forest Products, 5; 32-38 